\title{
Total ginsenosides induce autophagic cell death in cervical cancer cells accompanied by downregulation of bone marrow stromal antigen-2
}

\author{
SHUAI BIAN $^{1 *}$, YUE ZHAO $^{1 *}$, FANGYU LI $^{1}$, SHUYAN LU ${ }^{1}$, ZIYAN HE $^{2}$, SIMING WANG $^{1}$, \\ XUEYUAN BAI ${ }^{1}$, DAQING ZHAO ${ }^{1}$, MEICHEN LIU ${ }^{1}$ and JIAWEN WANG ${ }^{1}$ \\ ${ }^{1}$ Jilin Ginseng Academy, Changchun University of Chinese Medicine, Changchun, Jilin 130117; \\ ${ }^{2}$ College of Chemistry, Jilin University, Changchun, Jilin 13012, P.R. China
}

Received May 12,2020; Accepted March 15, 2021

DOI: $10.3892 / \mathrm{etm} .2021 .10099$

\begin{abstract}
Ginsenosides are important active components in Panax ginseng. In the present study, total ginsenosides (TGNs) were demonstrated to enhance autophagy by promoting acidic vacuole organelle formation, recruitment of enhanced green fluorescent protein-microtubule-associated protein light chain 3 and expression of autophagy-related factors in cervical cancer cell lines. TGN markedly increased the expression of p62 at the transcriptional level, but decreased p62 protein expression in the presence of actinomycin D. The autophagic regulatory effect was reversible. TGN $(\leq 120 \mu \mathrm{g} / \mathrm{ml})$ did not affect the proliferation of cervical cancer cells under normal culture conditions, but markedly inhibited the growth of serum-deprived cells. Treatment with an inhibitor of autophagy (3-methyladenine) impaired TGN-induced cell death. This suggested that TGN caused autophagic cell death. In addition, western blot analysis demonstrated that the protein level of bone marrow stromal antigen-2 (BST-2) was downregulated by TGN. Upregulation of BST-2 reduced cell death. The results of the combined actions of various monomeric ginsenosides in TGN provide the molecular basis to develop TGN as a promising candidate for cancer therapy.
\end{abstract}

\section{Introduction}

Autophagy is a vital metabolic process in eukaryotic cells, which plays a significant role in regulation of cell survival and death (1). Excessive autophagy disrupts cellular functions,

Correspondence to: Dr Jiawen Wang or Dr Meichen Liu, Jilin Ginseng Academy, Changchun University of Chinese Medicine, 1035 Boshuo Road, Changchun, Jilin 130117, P.R. China

E-mail: wangjiawen1229@163.com

E-mail: liumc0367@163.com

*Contributed equally

Key words: total ginsenosides, autophagy, autophagic cell death, bone marrow stromal antigen-2, cervical cancer which directly results in autophagic programmed cell death or apoptotic cell death. In certain cases, autophagy counteracts apoptotic cell death via a cell survival pathway (2). Cervical cancer is the second most prevalent type of malignancy in females (3). The primary and most common anticancer therapy for cervical cancer is chemotherapy. However, tumour cells develop intrinsic resistance against chemotherapy. Plant-derived compounds characterised by low toxicity and a wide range of anticancer activities present as promising novel anticancer agents (4).

Panax ginseng C.A. Meyer is a type of traditional medicinal plant that has been widely used in Asian regions for thousands of years (5). Ginsenosides, some of the most important active components in Panax ginseng, exert numerous pharmacological actions, including marked suppression of the proliferation and migration of tumour cells (5). Different ginsenoside monomers have different effects on autophagy in cancer cells and act on different pathways $(6,7)$. A recent study suggested that total ginsenoside (TGN) extract induces autophagic cell death in non-small cell lung cancer cells (8). However, the TGN concentrations used in the study were considered to be high $(0.125-1 \mathrm{mg} / \mathrm{ml})$ and the changes in p62 expression were not discussed.

Bone marrow stromal antigen 2 (BST-2), also referred to as CD317, tetherin and HM1.24 is a multifunctional protein. It is an interferon-inducible type II transmembrane glycoprotein that functions as an NF- $\mathrm{KB}$ activator (9), host restriction factor that tethers virions on the cell membrane (10) and survival protein that increases cancer cell adhesion and resistance to apoptosis (11). Under various disease conditions, particularly malignancies, BST-2 has been reported to be upregulated (12). The increased expression of BST-2 mediates tumour growth, invasion and metastasis $(12,13)$. Therefore, BST-2 is upregulated in autophagy knockdown cells and associated with CD63, which may inhibit hepatitis $\mathrm{C}$ virus assembly or release (14). Another study indicated that a non-canonical autophagy pathway reminiscent of microtubule-associated protein light chain 3 (LC3)-associated phagocytosis contributes to viral protein $\mathrm{U}$ counteraction of BST-2 restriction (15). These data indicate that BST-2 is an autophagy-associated factor. 
The effect of TGN on autophagy of cervical cancer cells remains unclear. In the present study, the effect of TGN on autophagy in HeLa cells was investigated and TGN treatment was found to induce irreversible autophagy in a concentrationand time-dependent manner. TGN increased the expression of p62 at transcriptional and protein expression levels. Further experiments revealed that TGN promoted autophagic cell death under serum-deprived conditions accompanied by downregulation of BST-2, which is important for the survival of cancer cells.

\section{Materials and methods}

Antibodies and reagents. The following antibodies were used in the present study: Mouse anti-tubulin monoclonal antibody (mAb; cat. no. 627901; BioLegend, Inc.), rabbit anti-LC3 mAb, rabbit anti-beclin $1 \mathrm{mAb}$ (cat. nos. 12741 and 3498, respectively; Cell Signaling Technology, Inc.) and rabbit anti-BST-2 pAb (cat. no. BS5634; Bioworld Technology, Inc.). The secondary antibodies were HRP-conjugated goat anti-mouse and anti-rabbit immunoglobulin G (cat. nos. 115-035-003 and 111-585-003, respectively; Jackson ImmunoResearch Laboratories, Inc.). Ginsenoside $\mathrm{Rb}_{1}, \mathrm{Rb}_{2}, \mathrm{Rc}, \mathrm{Rd}, \mathrm{Rg}_{1}, \mathrm{Rg}_{2}$ and Rf (purity, >98\%) were purchased from Chengdu Must Bio-Technology Co., Ltd. Acridine orange, lysis buffer and a Braford assay kit were purchased from Beyotime Institute of Biotechnology. Cell counting kit-8 (CCK-8) was purchased from Boster Biological Technology. Rapamycin, bafilomycin A1 and 3-methyladenine (3-MA) were purchased from InvivoGen. Actinomycin D was purchased from MedChemEpxress. Other ginsenosides were purchased from Chengdu Must Bio-Technology Co., Ltd. TRIzol ${ }^{\circledR}$ was purchased from Thermo Fisher Scientific, Inc. SYBR Premix Ex Taq ${ }^{\mathrm{TM}}$ and a reverse transcription kit were purchased from Takara Biotechnology Co., Ltd. The protein extraction buffer was purchased from Beyotime Institute of Biotechnology. Earle's Balanced Salt Solution (EBSS) was purchased from Beijing Solarbio Science \& Technology Co., Ltd.

Preparation of TGN. Ginseng crude powder (1 kg) was soaked in water overnight and extracted four times in boiling water for $3 \mathrm{~h}$ each time. The water-soluble substances were collected, applied to a D101 macroporous resin column and eluted with EtOH: $\mathrm{H}_{2} \mathrm{O}(0: 100,75: 25 ; \mathrm{v} / \mathrm{v})$. The eluent was condensed and evaporated to obtain TGN.

Analysis of TGN by high-performance liquid chromatography (HPLC). To analyse ginsenoside monomers, an Agilent 1260 series high performance liquid chromatograph, Agilent system chemistry workstation and Agilent 1260 UV-visible wavelength detector were used. A Sepax Bio-C18 HPLC column (5 $\mu \mathrm{m} ; 4.6 \times 250 \mathrm{~mm})$ was used for ginsenoside separation. The temperature of the column was maintained at $40^{\circ} \mathrm{C}$. The mobile phase consisted of solvent A (acetonitrile) and solvent $\mathrm{B}$ (water). The gradient elution program was as follows: 0-45 min, A 19\%; 45-50 min, A 19-27\%; 50-60 min, A $27-31 \%$; $60-70 \mathrm{~min}$, A $31-28 \%$; 70-85 min, A $28-35 \%$; $85-100 \mathrm{~min}$, A $35 \%$. The flow rate was set at $1 \mathrm{ml} / \mathrm{min}$. The quantitative method used was an external standard method (16).
Cell culture and transfection. The following cell lines were obtained from the American Type Culture Collection: HeLa (cat. no. CCL-2), MS751 (cat. no. HTB-34) and C-33A (cat. no. HTB-31) and were cultured in DMEM (Invitrogen; Thermo Fisher Scientific, Inc.) supplemented with $10 \%$ fetal bovine serum at $37^{\circ} \mathrm{C}$ with $5 \% \mathrm{CO}_{2}$. Culture under serum deprivation condition was culture in DMEM (Invitrogen; Thermo Fisher Scientific, Inc.) at $37^{\circ} \mathrm{C}$ with $5 \% \mathrm{CO}_{2}$. Enhanced green fluorescent protein(EGFP)-LC3, BST-2 IHA and VR1012 have been described previously $(17,18)$. Lipofectamine ${ }^{\circledR} 2000$ (Invitrogen; Thermo Fisher Scientific, Inc.) was used for transient plasmid transfections. EGFP-LC3-II plasmid (500 ng) was transfected into HeLa, MS751 and C-33A cells. After $37^{\circ} \mathrm{C}$ for $24 \mathrm{~h}$, the cells were treated with dimethylsulfoxide (DMSO) or TGN for an additional $7 \mathrm{~h}$ and then analysed for fluorescence. ImageJ Software (v1.8.0; National Institutes of Health) was used for densitometric analysis. VR1012 or BST-2 IHA plasmid (50 ng) was transfected into HeLa, MS751 and C-33A cells. After incubation at $37^{\circ} \mathrm{C}$ for $24 \mathrm{~h}$, cells were treated with DMSO or TGN for an additional $24 \mathrm{~h}$ and then analysed via CCK-8 assay. Following overnight culture in 6 -well plates, HeLa cells were treated with Actinomycin D $(80 \mathrm{mM})$ at $37^{\circ} \mathrm{C}$ with $5 \% \mathrm{CO}_{2}$ for $24 \mathrm{~h}$. Following overnight culture in 6-well plates, cells were treated with $1 \mathrm{ml}$ EBSS at $37^{\circ} \mathrm{C}$ for $3 \mathrm{~h}$.

Western blotting. After overnight culture in 6-well plates, HeLa cells were treated with DMSO or TGN $(40 / 60 / 80 \mu \mathrm{g} / \mathrm{ml})$ for $24 \mathrm{~h}$. Cells were harvested by centrifugation $(800 \mathrm{x} \mathrm{g}$; $25^{\circ} \mathrm{C}$; $5 \mathrm{~min}$ ), resuspended in RIPA total protein extraction lysis buffer (cat. no. BD0031; Bioworld Technology, Inc.) and BCA was used to detect the protein content. The loading buffer was added and boiled for $15 \mathrm{~min}$. A total of $8 \mu \mathrm{g}$ protein/lane was separated by SDS-PAGE on a $12 \%$ gel and the separated proteins were transferred to nitrocellulose membranes (Whatman plc; Cytiva). The membranes were blocked with $5 \%$ dry non-fat milk (BD Biosciences) for $30 \mathrm{~min}$ at room temperature. After washing in PBST 3 times, the membranes were incubated with the primary antibodies detailed in Antibodies and reagents (dilution, 1:1,000) overnight at $4^{\circ} \mathrm{C}$, washed with in PBST three times and then incubated with a secondary antibody as detailed in Antibodies and reagents (dilution, 1:1,000) for $1 \mathrm{~h}$ at room temperature. Protein bands were visualised using the Ultra High Sensitivity ECL Substrate kit (Beyotime Institute of Biotechnology). Immunoreactivity was visualised by chemiluminescence and densitometric analysis was performed with ImageJ Software (v1.8.0). The western blots in Fig. 3 are from cells following treatment with $80 \mu \mathrm{g} / \mathrm{ml} \mathrm{TGN}$ for $16 \mathrm{~h}$ or EBSS at $37^{\circ} \mathrm{C}$ for $3 \mathrm{~h}$. The compounds were washed out and proteins were extracted at the indicated time points.

Reverse transcription-quantitative PCR (RT-qPCR). Following overnight culture in 6-well plates, HeLa cells were treated with DMSO or TGN for $24 \mathrm{~h}$. Following centrifugation $\left(800 \times \mathrm{g} ; 25^{\circ} \mathrm{C} ; 5 \mathrm{~min}\right)$, the cells were collected and washed in PBS three times. Total RNA was extracted with TRIzol and reverse transcribed into cDNA using the reverse transcription kit. The PCR primers used were as follows: p62 forward, 5'-GCCAGAGGAACAGATGGAGT-3' and reverse, 5'-TCC 
Table I. Main components and contents of total ginsenosides.

\begin{tabular}{lc}
\hline Type & Content $(\%)$ \\
\hline $\mathrm{Rb}_{1}$ & 16.60 \\
$\mathrm{Rb}_{2}$ & 11.53 \\
$\mathrm{Rc}$ & 9.90 \\
$\mathrm{Rd}$ & 6.80 \\
$\mathrm{Rg}_{1}$ & 3.30 \\
$\mathrm{Rg}_{2}$ & 0.98 \\
$\mathrm{Rf}$ & 1.40 \\
Total & 50.51 \\
\hline
\end{tabular}

GATTCTGGCATCTGTAG-3'; BST-2 forward, 5'-CTGCAA CCACACTGTGATG-3' and reverse, 5'-ACGCGTCCTGAA GCTTATG-3'; GAPDH forward, 5'-GGTGAAGGTCGGAGT CAACGGA-3' and reverse, 5'-GAGGGATCTCGCTCCTGGA AGA-3'. RT-qPCR was performed using a SYBR Premix Ex Taq kit and the CFX Connect ${ }^{\mathrm{TM}}$ Real-Time system (Bio-Rad Laboratories, Inc.). The thermal cycling conditions were as follows: $95^{\circ} \mathrm{C}$ for $3 \mathrm{~min} ; 40$ cycles of $95^{\circ} \mathrm{C}$ for $10 \mathrm{sec}$ and $55^{\circ} \mathrm{C}$ for $30 \mathrm{sec} ; 95^{\circ} \mathrm{C}$ for $10 \mathrm{sec} ; 65^{\circ} \mathrm{C}$ for $5 \mathrm{sec}$ and $95^{\circ} \mathrm{C}$ for $5 \mathrm{sec}$. Data were calculated relative to a calibrator according to the $2^{-\Delta \Delta C a}$ method (19).

Acidic vesicular organelle (AVO) staining assay. After rinsing in PBS and fixing with $4 \%$ paraformaldehyde $25^{\circ} \mathrm{C}$ for $10 \mathrm{~min}$, the cells were stained for AVOs in the dark $37^{\circ} \mathrm{C}$ for $30 \mathrm{~min}$. Stained cells were observed and imaged by fluorescence microscopy (excitation, $488 \mathrm{~nm}$ ).

Cell Counting Kit (CCK)-8 assay. Cells were cultured overnight in 96-well plates. The next day, the culture supernatant was replaced with medium containing DMSO or TGN and the cells were incubated $37^{\circ} \mathrm{C}$ for $40 \mathrm{~min}$. For analysis, CCK- 8 substrate was added to the 96-well plates, followed by incubation at $37^{\circ} \mathrm{C}$ for $1 \mathrm{~h}$. Absorbance was measured at $450 \mathrm{~nm}$ using an Infinite 200 PRO microplate reader (Tecan Group, Ltd.). The cells in Fig. $4 \mathrm{C}$ were treated with $80 \mu \mathrm{g} / \mathrm{ml}$ TGN and 3 -MA for $24 \mathrm{~h}$ and cell viability detected via Cell Counting Kit-8 assays.

Statistical analysis. All data represent at least three independent experiments, which were evaluated statistically by one-way ANOVA and Dunnett's post hoc test. $\mathrm{P}<0.05$ was considered to indicate a statistically significant difference. The statistical analysis software was GraphPad Prism 7.0 (GraphPad Software Inc.).

\section{Results}

TGN induces cervical cancer cell autophagy in a timeand concentration-dependent manner. A TGN extract of ginseng root was analysed by HPLC. The chromatograms, including standard and sample chromatograms are presented in Fig. S1. The main components and contents of TGN are presented in Table I. The retention times specified
Table II. Retention time of total ginsenosides.

\begin{tabular}{lc} 
Type & Retention time (min) \\
\hline $\mathrm{Rg}_{1}$ & 31.863 \\
$\mathrm{Re}$ & 33.853 \\
$\mathrm{Rf}$ & 60.595 \\
$\mathrm{Rg} 2$ & 65.816 \\
$\mathrm{Rb} 1$ & 70.277 \\
$\mathrm{Rb} 2$ & 82.749 \\
$\mathrm{Rb} 3$ & 84.051 \\
$\mathrm{Rd}$ & 88.941 \\
\hline
\end{tabular}

are presented in Table II. To determine the effect of TGN on autophagy, the expression levels of autophagy factors in TGN-treated HeLa, MS751 and C-33A cells were investigated. TGN was observed to increase the processing of LC3-I to LC3-II in a time- and dose-dependent manner, as well as increase the expression of autophagy-related factor Beclin-1 in the three types of cervical cancer cells (Fig. 1A and B).

Next, an EGFP-LC3-II plasmid (500 ng) was transfected into HeLa, MS751 and C-33A cells. After $24 \mathrm{~h}$, the cells were treated with DMSO or TGN for an additional $7 \mathrm{~h}$ and then analysed for fluorescence. As shown in Fig. 2A, TGN promoted an increase in EGFP-LC3-II puncta. To further detect autophagy activation, the formation of AVOs in the three types of TGN-treated cervical cancer cells was analysed by AVO staining. Fig. 2B shows that a large number of AVOs appeared following treatment in a dose-dependent manner. These results suggested that TGN induced cervical cancer cell autophagy in a time- and concentration-dependent manner.

TGN increases transcription of p62 independent of autophagy. SQSTM1/p62 is a substrate for autophagy, which should be degraded following autophagy activation. However, p62 changes can be specific to the cell type and context. Occasionally, the expression level of p62 changes independent of autophagy (20-22). Furthermore, p62 may be transcriptionally upregulated under certain conditions (23). In the present study, western blotting demonstrated increases in p62 protein levels following TGN treatment (Fig. S2A). RT-qPCR analysis was performed to evaluate the transcriptional level of p62 after TGN treatment, which confirmed that p62 accumulation was due to transcriptional activation (Fig. S2B). To assess the change in p62 protein level, transcription inhibitor actinomycin D was used to eliminate the interference caused by increased transcription. TGN markedly decreased $\mathrm{p} 62$ protein levels in the presence of actinomycin D (Fig. S2C and D). These results further confirmed that TGN induced autophagy and increased transcription of p62 independent of autophagy.

The effect of TGN on autophagy promotion is irreversible. Subsequently, whether autophagy activation was reversible in the three cervical cancer cell lines was determined. EBSS is 
A

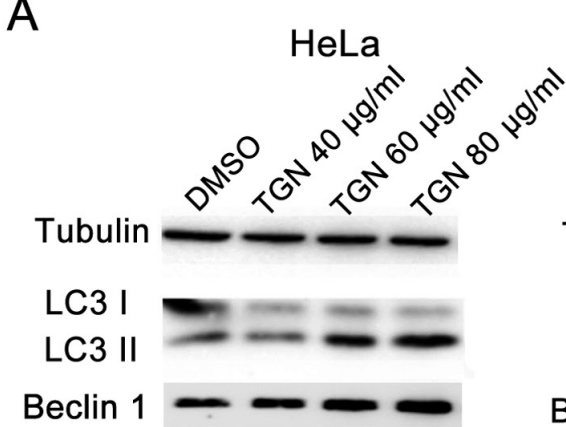

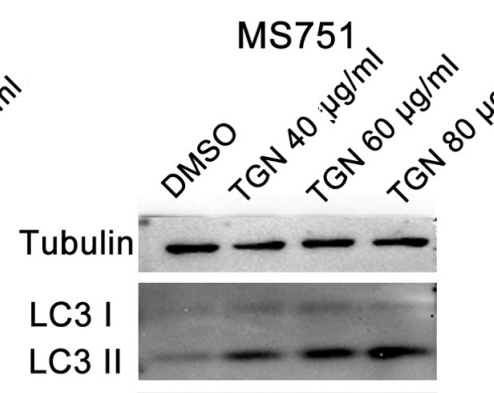

Beclin 1

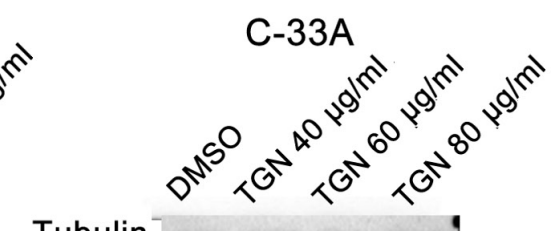

Tubulin $^{-}$

LC3 I

LC3 II

\section{Beclin 1}

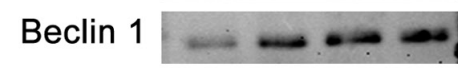

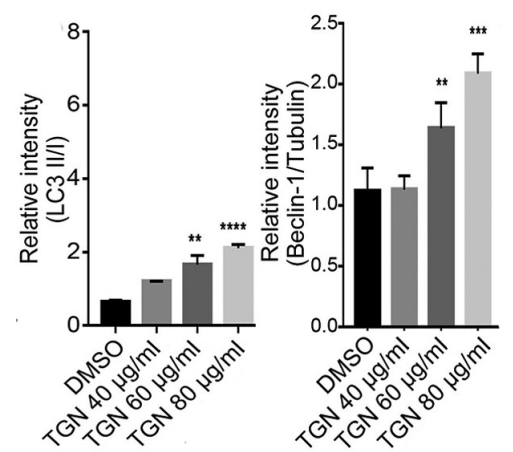

B

HeLa

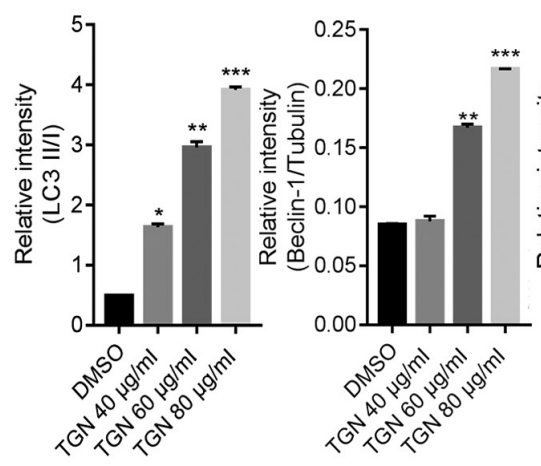

MS751

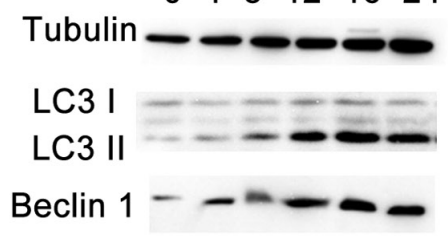

$\begin{array}{llllll}0 & 4 & 8 & 12 & 16 & 24 \mathrm{~h}\end{array}$

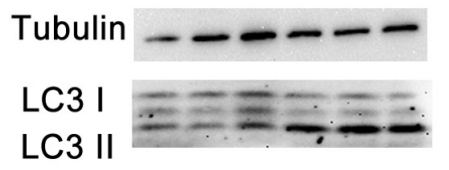

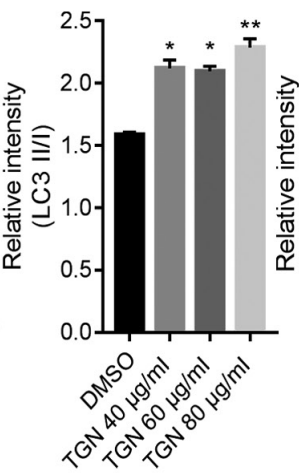

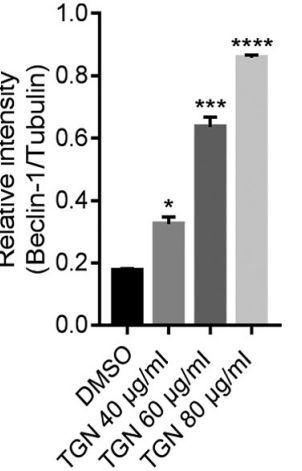

C-33A

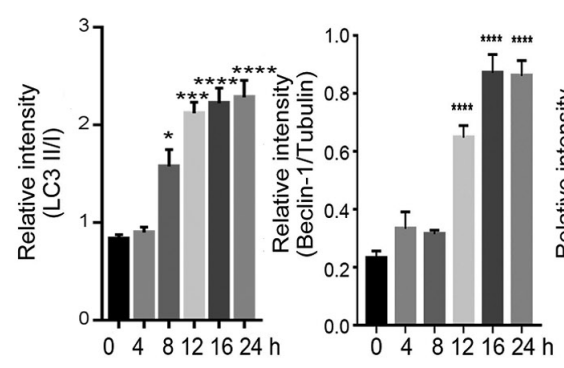

Beclin 1-- - -

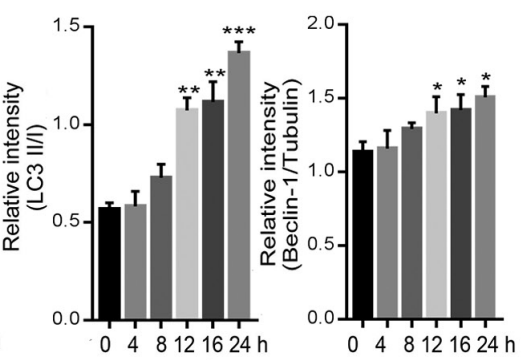

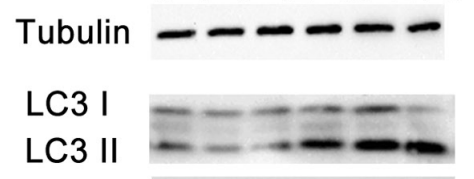

Beclin 1

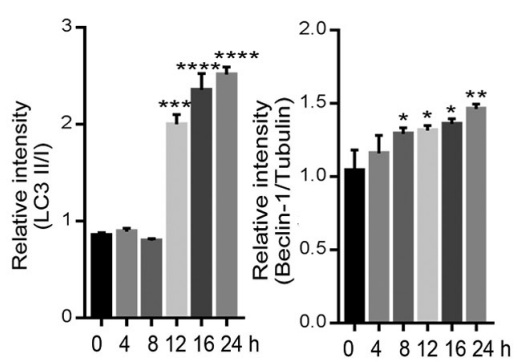

Figure 1. TGN induces cell autophagy in cervical cancer cell lines, HeLa, MS751 and C-33A in a (A) dose- and (B) time-dependent manner. Western blot analysis was performed with antibodies specific for Beclin-1, LC3 I/II and control protein, tubulin, followed by statistical analysis of the results; the values are presented as means \pm SD. ${ }^{*} \mathrm{P}<0.05,{ }^{* *} \mathrm{P}<0.01,{ }^{* * *} \mathrm{P}<0.001$ and ${ }^{* * * * *} \mathrm{P}<0.0001$ vs. DMSO. DMSO, dimethylsulfoxide; TGN, total ginsenoside; LC3, microtubule-associated protein light chain 3.

used for the short-term maintenance of cells in a $\mathrm{CO}_{2}$ environment and induces reversible autophagy (6). As shown in Fig. 3A-C, the activation of autophagy was not relieved even at $6 \mathrm{~h}$ after removal of TGN. Furthermore, the ratio of LC3-II/I continued to increase. However, EBSS-induced autophagy was rapidly relieved after replacing the medium. These data indicated that the effect of TGN on autophagy was irreversible over a short time period. The effects of ginsenoside monomers on autophagy showed that major components of TGN promoted autophagy, except ginsenoside Rf (Fig. 3D). These results differed from previous studies (8), which may be due to the use of different cell lines.
Reduction of BST-2 enhances cervical cancer cell death. Next, the cytotoxicity of TGN in the three types of cervical cancer cells was assessed via CCK-8 assay. TGN $(\sim 120 \mu \mathrm{g} / \mathrm{ml})$ had no effect on the proliferation of HeLa, MS751 or C-33A cells (Fig. 4A). Serum deprivation is often used to emulate the tumour microenvironment. Therefore, the cells were exposed to TGN under serum deprivation and then cell viability was assessed. As a result, TGN notably suppressed cell growth in a dose- and time-dependent manner (Fig. 4B). To determine whether cell death was caused by the combination of nutrient deficiency and TGN, autophagy inhibitor 3-MA was introduced into the 


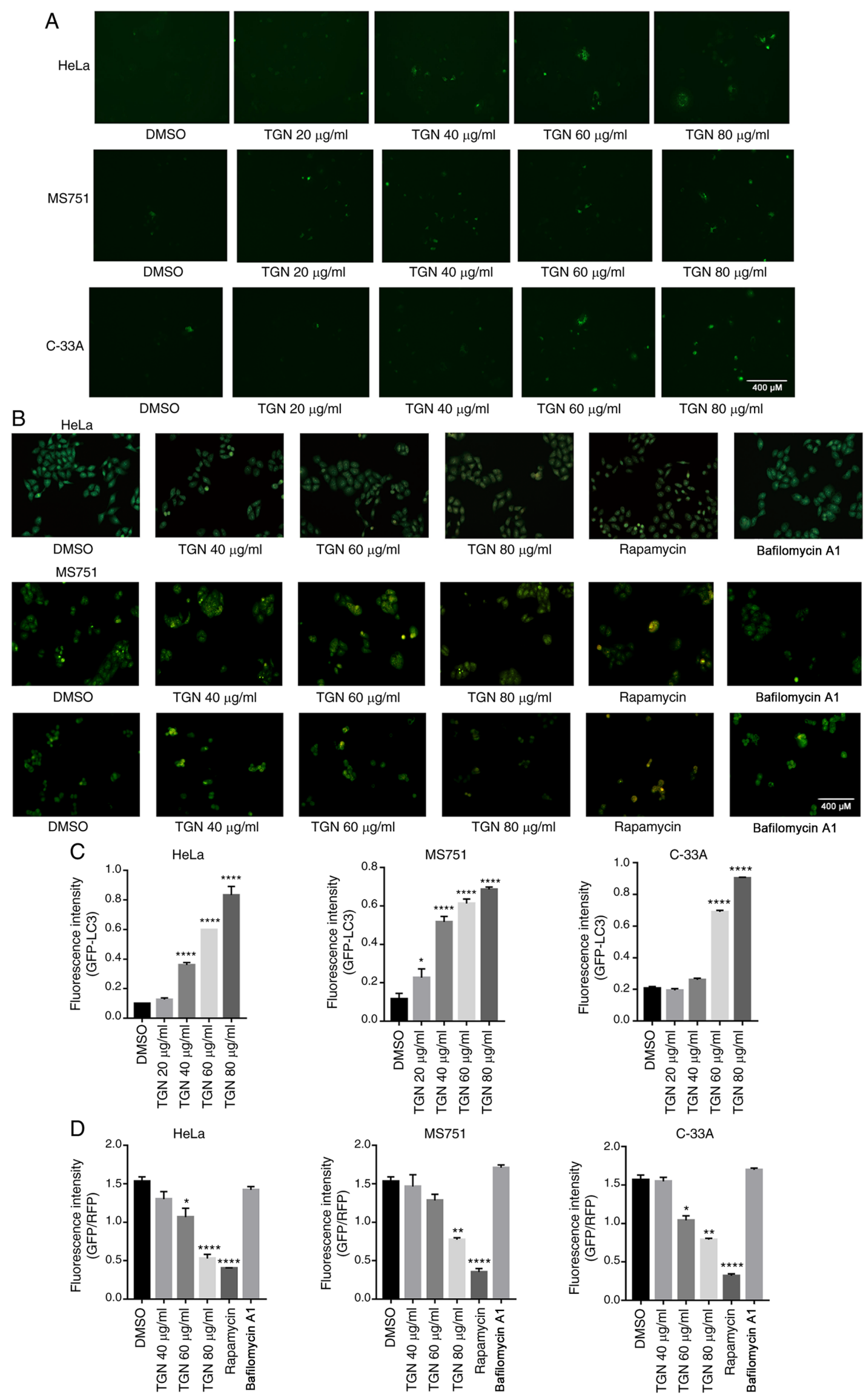

Figure 2. TGN increased EGFP-LC3 puncta and the quantity of AVOs. (A) TGN treatment markedly increased EGFP-LC3 puncta as observed by fluorescence microscopy. (B) AVOs were examined by incubating HeLa, MS751 and C-33A cells with acridine orange and observed by fluorescence microscopy. (C) Quantification of EGFP-LC3 puncta observed by fluorescence microscopy. (D) Quantification of AVOs stained with acridine orange and observed by fluorescence microscopy. Values are presented as means $\pm \mathrm{SD}$. ${ }^{*} \mathrm{P}<0.05,{ }^{* * *} \mathrm{P}<0.01$ and ${ }^{* * * * *} \mathrm{P}<0.0001$ vs. DMSO. TGN, total ginsenoside; EGFP-LC3, enhanced green fluorescent protein microtubule-associated protein light chain 3; AVO, acidic vesicular organelle; DMSO, dimethylsulfoxide. 
A

HeLa
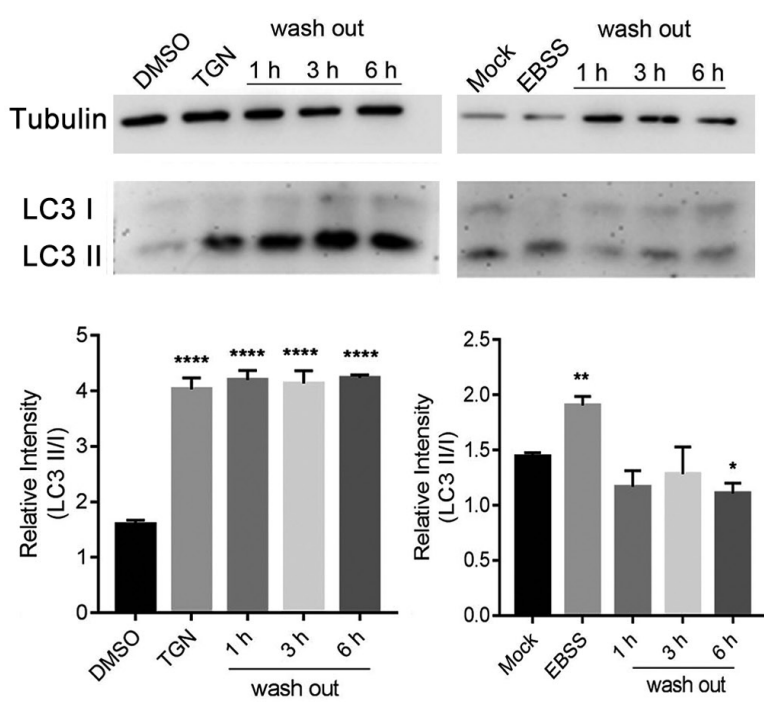

C

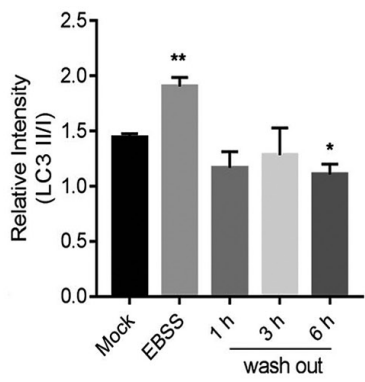

C-33A
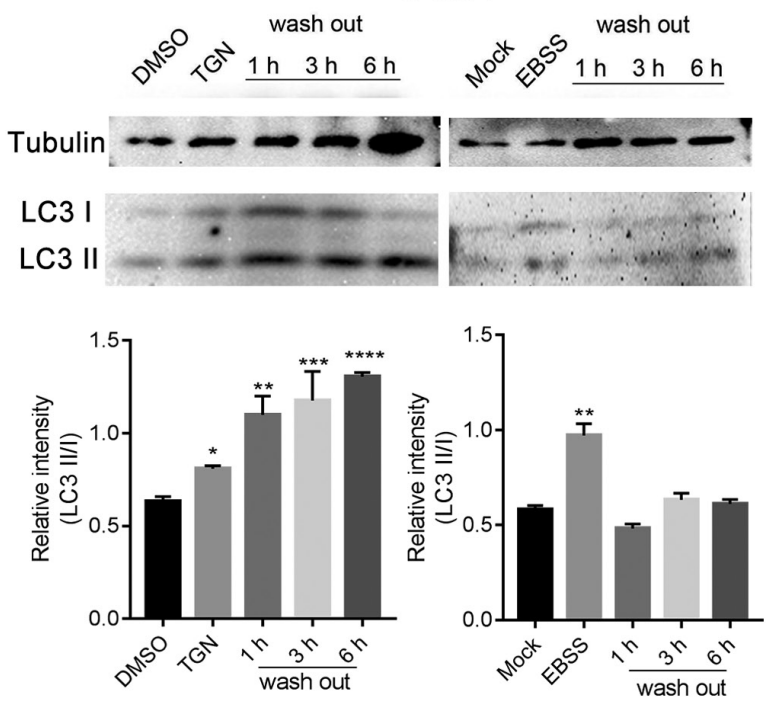

B

MS751
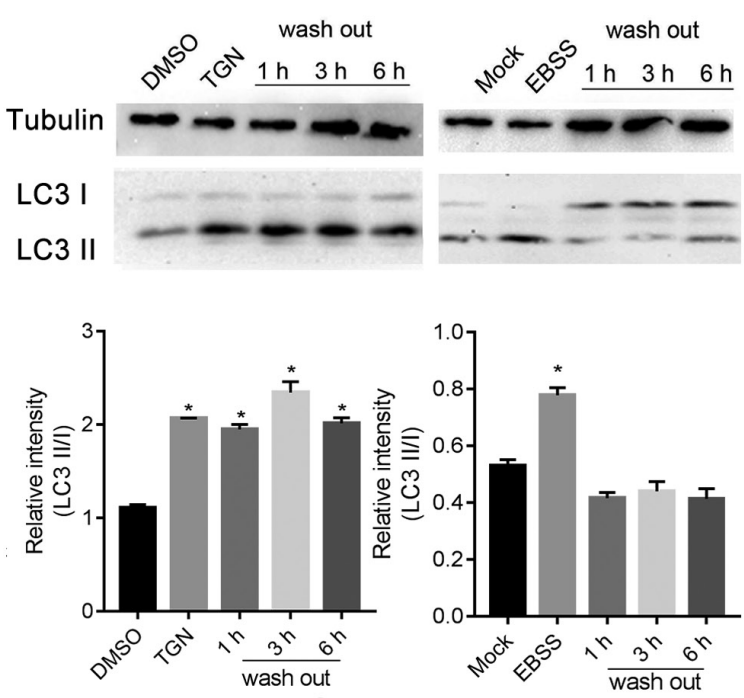

D
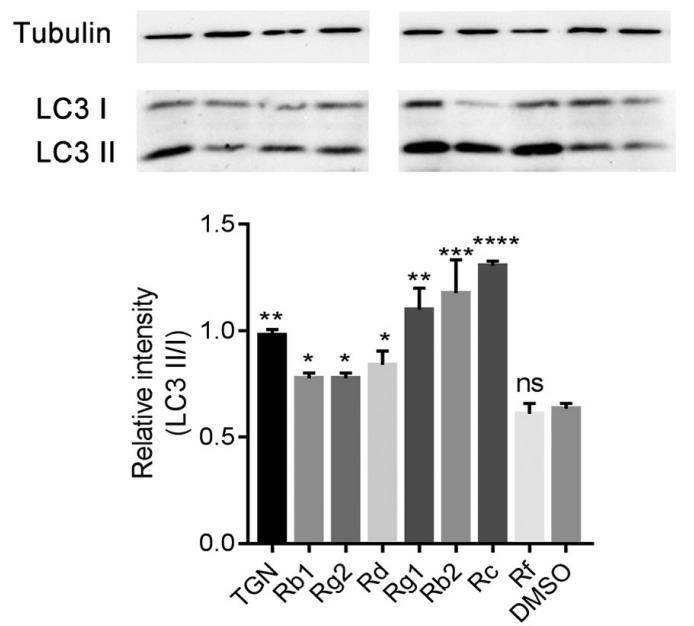

Figure 3. Autophagy is maintained for a long duration even after removing TGN. Western blots of (A) HeLa, (B) MS751 and (C) C-33A cells following treatment with $80 \mu \mathrm{g} / \mathrm{ml} \mathrm{TGN}$ for $16 \mathrm{~h}$ or EBSS for $3 \mathrm{~h}$. The compounds were washed out and proteins were extracted at the indicated time points. Statistical analysis of the western blots is also presented. (D) HeLa cells were treated with different ginsenosides for $16 \mathrm{~h}(60 \mu \mathrm{g} / \mathrm{ml} \mathrm{TGN}$; $70 \mu \mathrm{M}$ ginsenosides monomer), cell lysates were detected with an LC 3 antibody and tubulin served as the loading control. Values are presented as means $\pm \mathrm{SD}$. ${ }^{*} \mathrm{P}<0.05,{ }^{* *} \mathrm{P}<0.01,{ }^{*}{ }^{* *} \mathrm{P}<0.001$ and ***** $\mathrm{P}<0.0001$ vs. DMSO or Mock; ns, not significant. TGN, total ginsenoside; LC3, microtubule-associated protein light chain 3; DMSO, dimethylsulfoxide; EBSS, Earle's Balanced Salt Solution.

experiment. TGN-induced cell death was partly weakened by 3 -MA, indicating that TGN induced autophagic cell death (Fig. 4C).

The expression of BST-2 is associated with various types of cancer. Therefore, the protein level of BST-2 was analysed in TGN-treated cells. The transcription and protein expression levels of BST-2 were observed to be downregulated in TGN-treated cervical cancer cells in normal culture (Fig. 5A). To further confirm the association of BST-2 downregulation with cell death, a BST-2 expression plasmid was introduced into the experiment and a CCK-8 assay was used to evaluate cell viability. The result demonstrated that upregulation of BST-2 reduced cell death in a serum-deprived culture (Fig. 5B). These results indicated that TGN induced downregulation of BST-2 and promoted cervical cancer cell death in serum-deprived cultures.

\section{Discussion}

In recent years, there has been a rise in the morbidity and mortality of cancer, presenting a global health issue (24). Botanical medicines have been used to treat various types of disease in Asia for thousands of years, and ginseng is one of the most well-known and widely used oriental medicinal plants (24). Dried, steamed or heated ginseng is distributed in 35 countries in various forms (24). Previous studies have reported the beneficial effects of ginseng on diseases, such as cancer, immune disorders, diabetes, as well 
A
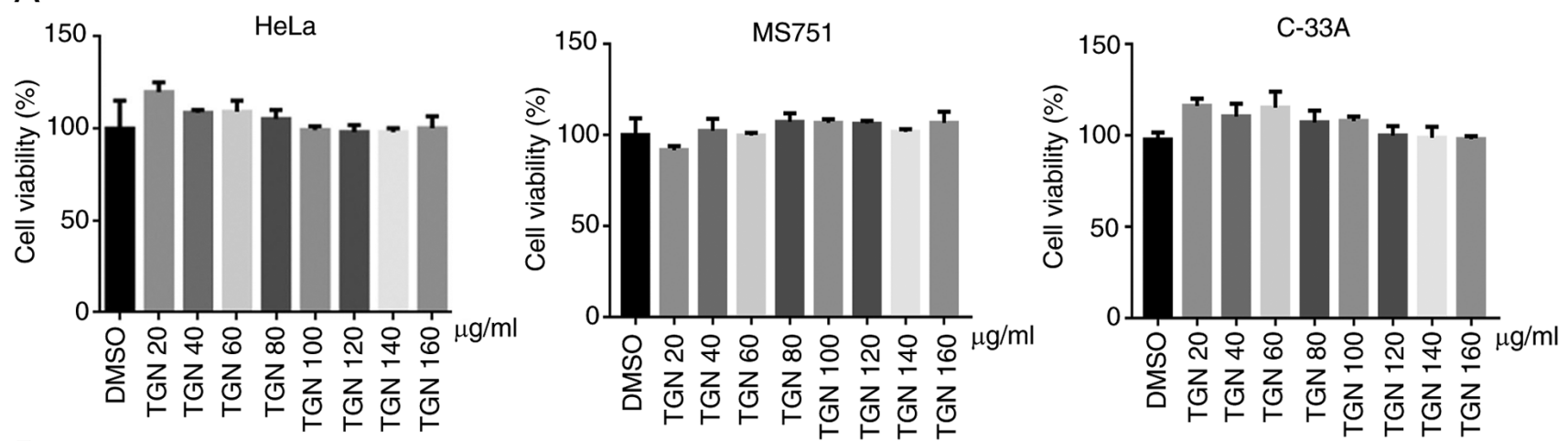

B
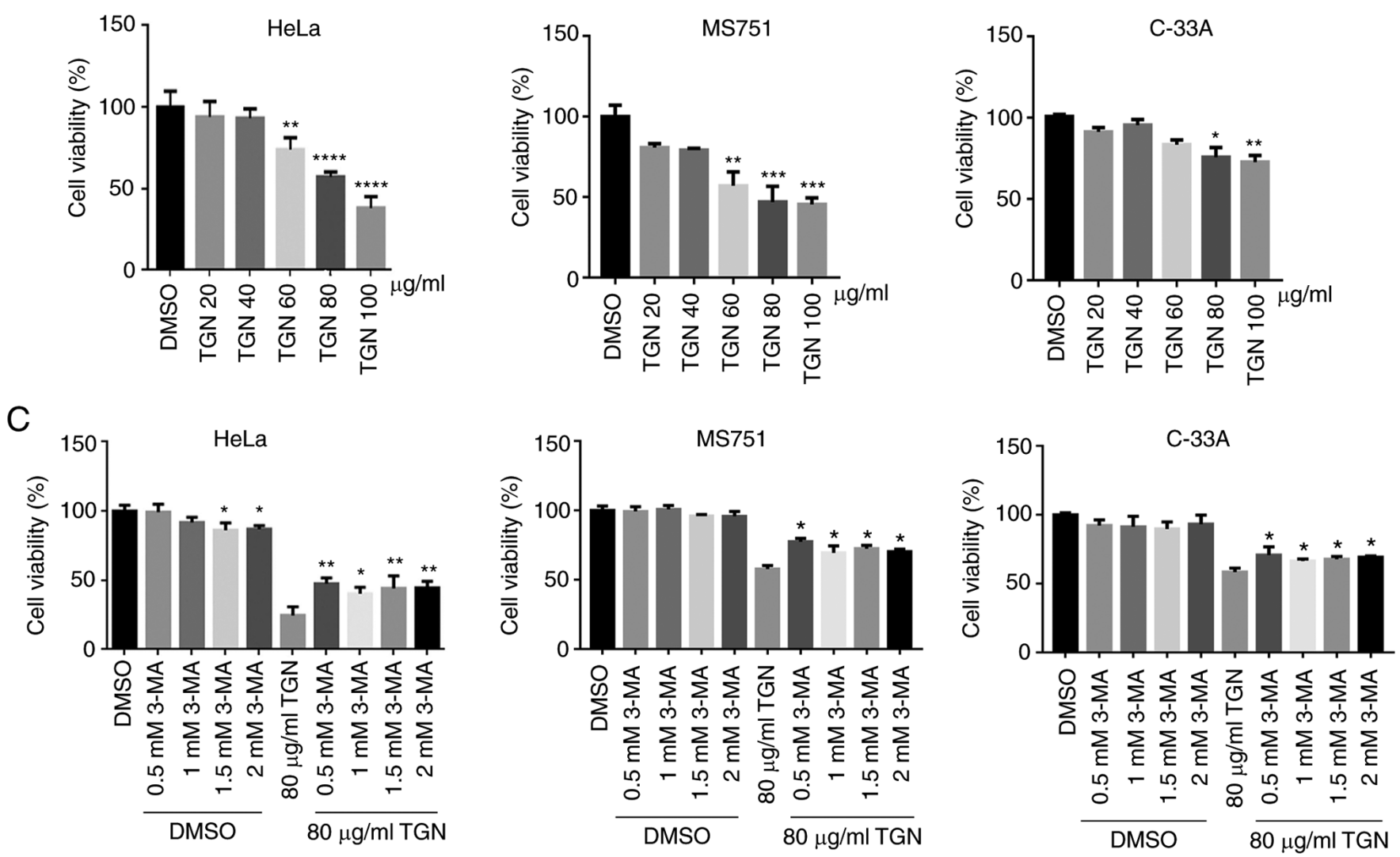

Figure 4. TGN induces autophagic cell death of cervical cancer cells under serum deprivation. (A) Effects of treatment with TGN at various concentrations on HeLa, MS751 and C-33A cells under normal conditions. (B) Effects of treatment with TGN at various concentrations on HeLa, MS751 and C-33A cells under serum-deprived conditions. (C) HeLa, MS751 and C-33A cells were treated with $80 \mu \mathrm{g} / \mathrm{ml}$ TGN with 3-MA for $24 \mathrm{~h}$ and then cell viability was detected via Cell Counting Kit- 8 assays. ${ }^{*} \mathrm{P}<0.05,{ }^{* *} \mathrm{P}<0.01,{ }^{* * *} \mathrm{P}<0.001$ and ${ }^{* * * * *} \mathrm{P}<0.0001$ vs. DMSO. TGN, total ginsenoside; $3-\mathrm{MA}, 3-\mathrm{methyladenine}$; DMSO, dimethylsulfoxide.

as on liver, nervous system, cardiovascular and infectious diseases (25-31).

BST-2 is an innate immune gene that is upregulated in various types of cancer, such as breast cancer, mammary tumours and bladder cancer (32-34). Dimers of BST-2 promote cell-cell and cell-matrix adhesions, cell motility, survival and growth (35). It also protects cervical cancer cells from serum deprivation-induced death (35). A BST-2-based peptide, known as B49 and its analogue, B49Mod1 inhibit adhesion and growth of breast cancer cells $(35,36)$. Therefore, targeting BST-2 presents a potential therapeutic strategy against cancer (37-39). BST-2 is an autophagy-associated protein. It is hypothesized to be a substrate of autophagy. In the present study, the expression level of BST-2 was identified to be decreased in TGN-treated cells and accompanied by increasing cell death. The underlying mechanism may be that BST-2 was degraded through induced autophagy and increased the death of serum-deprived cells.

Therefore, TGN enhanced irreversible autophagy in cervical cancer cell lines and caused significant autophagic cell death in serum-deprived cells. TGN markedly increased the expression of p62 at the transcriptional level, but decreased p62 protein levels in the presence of actinomycin D. Furthermore, protein expression levels of BST-2 were downregulated by TGN and upregulation of BST-2 reduced the 
A

HeLa
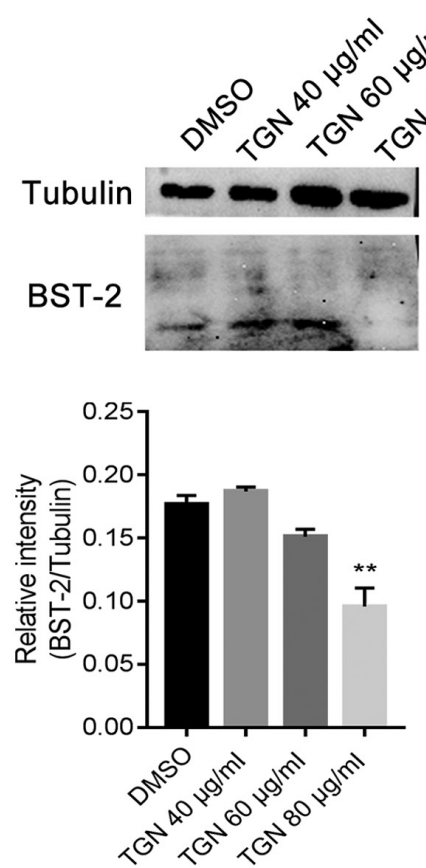

B

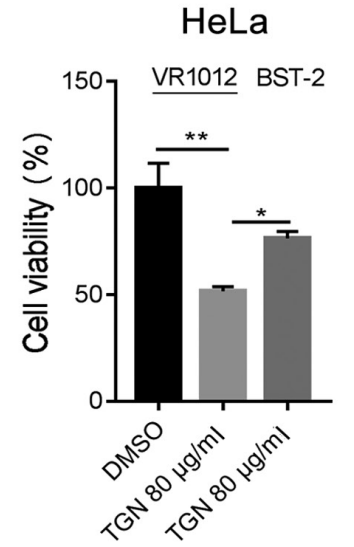

MS751

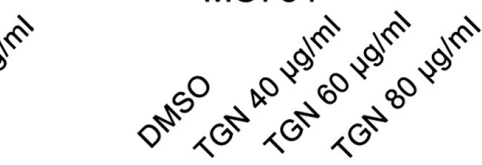

Tubulin

BST-2
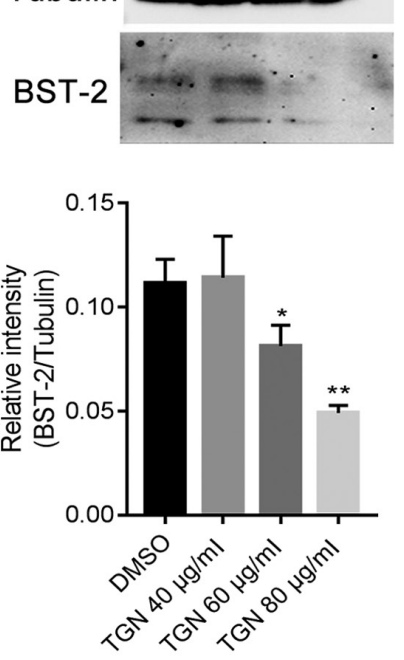

MS751

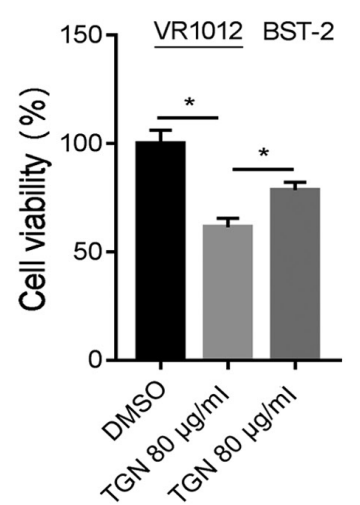

C-33A
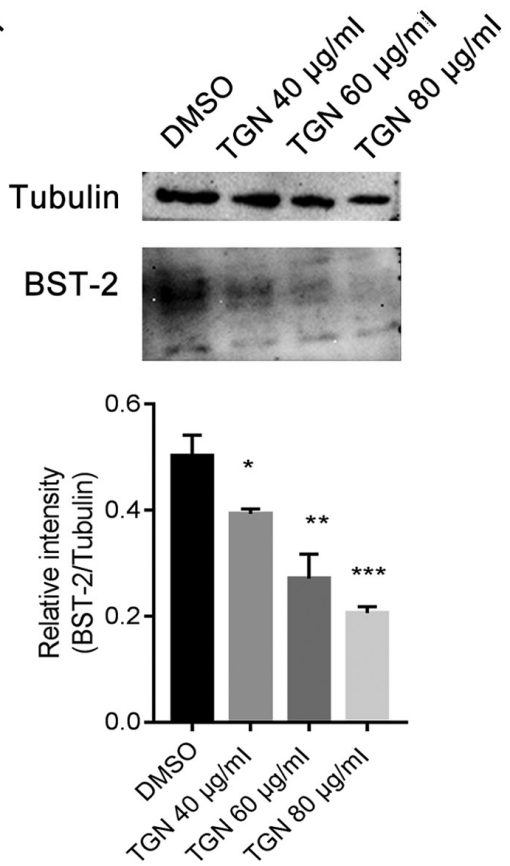

C-33A

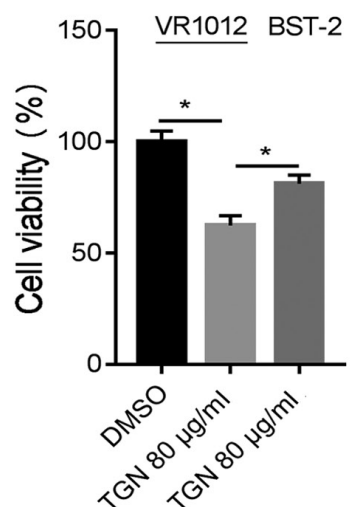

Figure 5. TGN induced downregulation of BST-2 and promoted cervical cancer cell death in serum-deprived cultures. (A) After cells were treated with $80 \mu \mathrm{g} / \mathrm{ml} \mathrm{TGN}$ for $16 \mathrm{~h}$, the protein expression levels of BST-2 was determined by western blotting. (B) Cell viability in the serum-deprived culture was detected via Cell Counting Kit- 8 assays following BST-2 overexpression. ${ }^{*} \mathrm{P}<0.05,{ }^{* *} \mathrm{P}<0.01,{ }^{* * *} \mathrm{P}<0.001$ vs. DMSO. TGN, total ginsenoside; BST-2, bone marrow stromal antigen-2; DMSO, dimethylsulfoxide.

cell death that was caused by TGN. These results provide the molecular basis to develop TGN as a promising candidate for cancer therapy.

\section{Acknowledgements}

Not applicable.

\section{Funding}

The present study was supported by the National Key Research and Development Program of China (grant no. 2017YFC1702104), the Key Project at Central Government Level: The ability establishment of sustainable use for valuable Chinese medicine resources (grant no. 2060302) and the Cultivation Fund Project of Changchun University of Chinese Medicine (grant no. 2018KJ03).

\section{Availability of data and materials}

The datasets used and/or analysed during the current study are available from the corresponding author on reasonable request.

\section{Authors' contributions}

JW, ML and SB designed the experiments. SB, YZ, FL, SL, $\mathrm{ZH}$ and $\mathrm{SW}$ performed the experiments. ML, SW, XB, DZ analysed the experiments. JW wrote the paper. SB and JW confirm the authenticity of all the raw data. All authors read and approved the final version of the manuscript.

\section{Ethics approval and consent to participate}

Not applicable. 


\section{Patient consent for publication}

Not applicable.

\section{Competing interests}

The authors declare that they have no competing interests.

\section{References}

1. Yu L, Chen Y and Tooze SA: Autophagy pathway: Cellular and molecular mechanisms. Autophagy 14: 207-215, 2018.

2. Wang K: Autophagy and apoptosis in liver injury. Cell Cycle 14: $1631-1642,2015$

3. Finocchario-Kessler S, Wexler C, Maloba M, Mabachi N, Ndikum-Moffor F and Bukusi E: Cervical cancer prevention and treatment research in Africa: A systematic review from a public health perspective. BMC Womens Health 16: 29, 2016.

4. Wong AS, Che CM and Leung KW: Recent advances in ginseng as cancer therapeutics: A functional and mechanistic overview. Nat Prod Rep 32: 256-272, 2015.

5. Ahuja A, Kim JH, Kim JH, Yi YS and Cho JY: Functional role of ginseng-derived compounds in cancer. J Ginseng Res 42 : 248-254, 2018.

6. Zheng K, Li Y, Wang S, Wang X, Liao C, Hu X, Fan L, Kang Q, Zeng Y, Wu X, et al: Inhibition of autophagosome-lysosome fusion by ginsenoside Ro via the ESR2-NCF1-ROS pathway sensitizes esophageal cancer cells to 5-fluorouracil-induced cell death via the CHEK1-mediated DNA damage checkpoint. Autophagy 12: 1593-1613, 2016.

7. Zhuang J, Yin J, Xu C, Mu Y and Lv S: 20(S)-ginsenoside Rh2 induce the apoptosis and autophagy in U937 and K562 cells. Nutrients 10: 328, 2018 .

8. Zhao M, Chen Q, Xu W, Wang H, Che Y, Wu M, Wang L, Lijuan $\mathrm{C}$ and $\mathrm{Hao} \mathrm{H}$ : Total ginsenosides extract induce autophagic cell death in NSCLC cells through activation of endoplasmic reticulum stress. J Ethnopharmacol 243: 112093, 2019.

9. Tokarev A, Suarez M, Kwan W, Fitzpatrick K, Singh R and Guatelli J: Stimulation of NF- $\kappa$ B activity by the HIV restriction factor BST2. J Virol 87: 2046-2057, 2013.

10. Neil SJ,Zang T and Bieniasz PD: Tetherin inhibits retrovirus release and is antagonized by HIV-1 Vpu. Nature 451: 425-430, 2008.

11. Mahauad-Fernandez WD, DeMali KA, Olivier AK and Okeoma CM: Bone marrow stromal antigen 2 expressed in cancer cells promotes mammary tumor growth and metastasis. Breast Cancer Res 16: 493, 2014.

12. Fang KH, Kao HK, Chi LM, Liang Y, Liu SC, Hseuh C, Liao CT, Yen TC, Yu JS and Chang KP: Overexpression of BST2 is associated with nodal metastasis and poorer prognosis in oral cavity cancer. Laryngoscope 124: E354-E360, 2014.

13. Mukai S, Oue N, Oshima T, Mukai R, Tatsumoto Y, Sakamoto N, Sentani K, Tanabe K, Egi H, Hinoi T, Ohdan H and Yasui W: Overexpression of transmembrane protein BST-2 is associated with poor survival of patients with esophageal, gastric, or colorectal cancer. Ann Surg Oncol 24: 594-602, 2017.

14. Shrivastava S, Devhare P, Sujijantarat N, Steele R, Kwon YC, Ray R and Ray RB: Knockdown of autophagy inhibits infectious Hepatitis C Virus release by the exosomal pathway. J Virol 90: 1387-1396, 2015.

15. Madjo U, Leymarie O, Frémont S, Kuster A, Nehlich M Gallois-Montbrun S, Janvier K and Berlioz-Torrent C: LC3C contributes to Vpu-mediated antagonism of BST2/Tetherin restriction on HIV-1 release through a non-canonical autophagy pathway. Cell Rep 17: 2221-2233, 2016.

16. Qi AN, Mei G, Ya-Jun S, Ying Z, Rui-Luan W, Long G, Yu-Guang Z and Dan Z: Comparative study on changes of ginsenosides and activities of American ginseng before and after steaming. Zhongguo Zhong Yao Za Zhi 45: 4404-4410, 2020 (In Chinese).

17. Bian S, Zhao Y, Li F, Lu S, Wang S, Bai X, Liu M, Zhao D, Wang J and Guo D: 20(S)-Ginsenoside Rg3 promotes HeLa cell apoptosis by regulating autophagy. Molecules 24: 3655, 2019.

18. Lv M, Wang J, Zhang J, Zhang B, Wang X, Zhu Y, Zuo T, Liu D, $\mathrm{Li}$ X, Wu J,et al: Epitope tags beside the N-terminal cytoplasmic tail of human BST-2 alter its intracellular trafficking and HIV-1 restriction. PLoS One 9: e111422, 2014.

19. Livak KJ and Schmittgen TD: Analysis of relative gene expression data using real-time quantitative PCR and the 2(-Delta Delta C(T)) method. Methods 25: 402-408, 2001.
20. Nakasa K, Yoshimoto Y, Nakano T, Takeshima T, Fukuhara Y, Yasui K, Araga S, Yanagawa T, Ishii T and Nakashima K: Transcriptional activation of p62/A170/ZIP during the formation of the aggregates: Possible mechanisms and the role in Lewy body formation in Parkinson's disease. Brain Res 1012: 42-51, 2004.

21. Bardag-Gorce F, Francis T, Nan L, Li J, He Lue Y, French BA and Franch SW: Modifications in P62 occur due to proteasome inhibition in alcoholic liver disease. Life Sci 77: 2594-2602, 2005.

22. Kuusisto E, Suuronen T and Salminen A: Ubiquitin-binding protein p62 expression is induced during apoptosis and proteasomal inhibition in neuronal cells. Biochem Biophys Res Commun 280: 223-228, 2001

23. Klionsky DJ, Abdelmohsen K, Abe A, Abedin MJ, Abeliovich H, Acevedo Arozena A, Adachi H, Adams CM, Adams PD, Adeli K, et al: Guidelines for the use and interpretation of assays for monitoring autophagy (3rd edition). Autophagy 12: 1-222, 2016.

24. Wang W, Nishioka Y, Ozaki S, Jalili A, Abe S, Kakiuchi S, Kishuku M, Minakuchi K, Matsumoto T and Sone S: HM1.24 (CD317) is a novel target against lung cancer for immunotherapy using anti-HM1.24 antibody. Cancer Immunol Immunother 58: 967-976, 2009.

25. Shigematsu Y, Oue N, Nishioka Y, Sakamoto N, Sentani K, Sekino Y, Mukai S, Teishima J, Matsubara A and Yasui W: Overexpression of the transmembrane protein BST-2 induces Akt and Erk phosphorylation in bladder cancer. Oncol Lett 14: 999-1004, 2017.

26. Li X, Zhang G, Chen Q, Lin Y, Li J, Ruan Q, Chen Y, Yu G and Wan X: CD317 Promotes the survival of cancer cells through apoptosis-inducing factor. J Exp Clin Cancer Res 35: 117, 2016.

27. Mahauad-Fernandez WD and Okeoma CM: B49, a BST-2-based peptide, inhibits adhesion and growth of breast cancer cells. Sci Rep 8: 4305, 2018.

28. Lyu Y, Mahauad-Fernandez WD and Okeoma CM: Development and characterization of the shortest anti-adhesion peptide analogue of B49Mod1. Molecules 25: 1188, 2020.

29. Yokoyama T, Enomoto T, Serada S, Morimoto A, Matsuzaki S, Ueda Y, Yoshino K, Fujita M, Kyo S, Iwahori K, et al: Plasma membrane proteomics identifies bone marrow stromal antigen 2 as a potential therapeutic target in endometrial cancer. Int J Cancer 132: 472-484, 2013.

30. Schliemann C, Roesli C, Kamada H, Borgia B, Fugmann T, Klapper W and Neri D: In vivo biotinylation of the vasculature in B-cell lymphoma identifies BST-2 as a target for antibody-based therapy. Blood 115: 736-744, 2010.

31. Silveira NJ, Varuzza L, Machado-Lima A, Lauretto MS, Pinheiro DG, Rodrigues RV, Severino P, Nobrega FG; Head and Neck Genome Project GENCAPO, Silva WA Jr, et al: Searching for molecular markers in head and neck squamous cell carcinomas (HNSCC) by statistical and bioinformatic analysis of larynx-derived SAGE libraries. BMC Med Genomics 1: 56, 2008.

32. Im K, Kim J and Min H: Ginseng, the natural effectual antiviral: Protective effects of Korean Red Ginseng against viral infection. J Ginseng Res 40: 309-314, 2016.

33. Kim YR and Yang CS: Protective roles of ginseng against bacterial infection. Microb Cell 5: 472-481, 2018.

34. Benzie IFF and Wachtel-Galor S: Herbal medicine: Biomolecular and clinical aspects. Taylor \& Francis Group, Chapter 1: 1-11, 2011

35. Lee JS, Ko EJ, Hwang HS, Lee YN, Kwon YM, Kim MC and Kang SM: Antiviral activity of ginseng extract against respiratory syncytial virus infection. Int J Mol Med 34: 183-190, 2014.

36. Radad K, Gille G, Liu LL and Rausch WD: Use of ginseng in medicine with emphasis on neurodegenerative disorders. J Pharmacol Sci 100: 175-186, 2006.

37. Yoo DG, Kim MC, Park MK, Song JM, Quan FS, Park KM, Cho YK and Kang SM: Protective effect of Korean red ginseng extract on the infections by H1N1 and H3N2 influenza viruses in mice. J Med Food 15: 855-862, 2012.

38. Kim S, Lee Y and Cho J: Korean red ginseng extract exhibits neuroprotective effects through inhibition of apoptotic cell death. Biol Pharm Bull 37: 938-946, 2014.

39. Mahauad-Fernandez WD, Naushad W, Panzner TD, Bashir A, Lal $\mathrm{G}$ and Okeoma CM: BST-2 promotes survival in circulation and pulmonary metastatic seeding of breast cancer cells. Sci Rep 8: 17608, 2018.

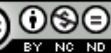

This work is licensed under a Creative Commons Attribution-NonCommercial-NoDerivatives 4.0 International (CC BY-NC-ND 4.0) License. 